This item was submitted to Loughborough's Research Repository by the author.

Items in Figshare are protected by copyright, with all rights reserved, unless otherwise indicated.

\title{
Anatomy of cascading natural disasters in Japan: main modes and linkages
}

\section{PLEASE CITE THE PUBLISHED VERSION}

http://dx.doi.org/10.1007/s11069-015-2028-8

\section{PUBLISHER}

(C) Springer Science and Business Media

\section{VERSION}

NA (Not Applicable or Unknown)

\section{PUBLISHER STATEMENT}

This work is made available according to the conditions of the Creative Commons Attribution-NonCommercialNoDerivatives 4.0 International (CC BY-NC-ND 4.0) licence. Full details of this licence are available at: https://creativecommons.org/licenses/by-nc-nd/4.0/

\section{LICENCE}

CC BY-NC-ND 4.0

\section{REPOSITORY RECORD}

Kumasaki, Mieko, Malcolm King, Mitsuru Arai, and Lili Yang. 2019. "Anatomy of Cascading Natural Disasters in Japan: Main Modes and Linkages”. figshare. https://hdl.handle.net/2134/20714. 
$\underline{\text { Anatomy of cascading natural disasters in Japan - main modes and linkages }}$

Mieko Kumasaki*, Malcolm King**, Mitsuru Arai***, Lili Yang**

*Yokohama National University

79-7 Tokiwadai Hodogaya Yokohama Kanagawa, 240-8501 Japan

kumasaki@ynu.ac.jp,

$+81-45-339-3994$

** Loughborough University

Loughborough Leicestershire, LE11 3TU United Kingdom

*** The University of Tokyo

7-3-1 Hongo Bunkyo Tokyo, 113-0033 Japan

\begin{abstract}
$\underline{\text { Abstract }}$
In order to contribute to the development of risk assessment, cascading natural disasters which are sequences of natural hazards was studied and the patterns of the interactions between natural disasters were investigated. The data was collected from the database of Japanese newspaper. The relationships between each natural hazards were emerged and divided into four modes: striking, undermining, compounding, and blocking modes. Striking mode means a primary disaster provides sufficient energy to move a significant mass or to propagate the energy through media. In undermining mode, a primary disaster lowers the resistance or weakens a system maintaining mass and caused to collapse. Compounding mode of the linkage shows that a primary disaster reduces the strength of a system. The difference from undermining mode is that this mode adds to the amount of mass affected. Blocking mode is found in an event blocking steady flows. The results are important for an understanding of the impact of these types of cascading natural disaster and so are valuable as a basis for the identification, description, and development of countermeasures.
\end{abstract}

\title{
$\underline{\text { Keywords }}$
}

Cascading natural disaster, risk assessment, interaction patters, striking, undermining, compounding, blocking 
2 Since natural disasters have massive power to threaten human lives, property and social and

3 cultural systems, immense effort has been made throughout human history to control such

4 hazards, limit consequences, or mitigate loss and damage. When a natural disaster happens,

5 the damage can be devastating and ruin civilization. History records how humans have

6 tackled these threats and developed countermeasures to mitigate the massive power and

7 enormous loss. For instance, some monarchs regarded flood control as their highest

8 responsibility. Hammurabi, an ancient king of Babylon, devoted most of the last nine years of

9 his reign to such projects and maintained canals for flood control as well as irrigation

10 (Bertman 2003; Levin 2009). Even now, a few thousand years since Hammurabi,

11 governments seek to combat the risk caused by both the old types of hazards and also new

12 ones emerging in the wake of the expansion of habitat and the development of human

13 activities.

14 Recently, sequences of disasters triggered by natural events have been highlighted. In the

15 sequences, one or more primary hazardous events trigger one or more secondary hazardous

16 events so that the initial disaster is compounded by the secondary event. These situations are

17 referred to as "multiple”, "cascading”, or "domino" disasters by different authors in the

18 relevant literature but in this paper we will use "cascading" to denote this type of situation.

19 One of the reasons for the current attention to these situations is the massive impact of the

20 earthquake and the subsequent tsunami which caused so much destruction and a humanitarian

21 crisis in Japan, 2011 (Krausmann and Cruz 2013).

22 The 2011 disaster in Japan is also considered as a "Natech", which denotes accidents

23 triggered by natural events that create technological calamities (Showalter and Myers 1992).

24 Natech risks can be found particularly at industrial sites storing hazardous materials due to

25 the concern about the loss of containment by destructive natural hazards. Moreover, natural

26 disasters can trigger multiple and simultaneous losses of containment and then require

27 simultaneous response efforts.

28 However, most of these studies have been limited to technological accidents initiated by a

29 single natural disaster. But, there are risks that the countermeasures against each individual

30 natural event, such as floods, tsunami, lightning, typhoon, earthquake, and so forth, may be

31 less effective when the initial event is coupled with another unexpected type of event. For

32 instance, remaining in an underground structure is considered relatively safe in the event of

33 an earthquake (Ohbo et al. 2004) but poses serious risks if a flood occurs (Shao 2010). For

34 the reliable risk management of natural disasters and their consequences, cascading natural

35 disasters should be investigated and incorporated into management strategies. This study will

36 focus exclusively on cascading natural disasters rather than Natech disasters.

37 So far, there have been some studies of cascading natural disaster. The importance of risk

38 assessment models applicable when several events have occurred at the same time or in a

39 successive manner has been emphasized by many. However, as yet, there are no international

40 standards and not even the basic knowledge to establish such standards. The lack of a good 
41 data foundation hinders progress in this field. As cascading natural events have the potential

42 to expand the damaged area, increase the number of affected people, and result in a much

43 greater impact on society than individual natural hazards, the linkages between natural

44 disasters needs to be unravelled.

45 This study investigates cascading natural disasters and seeks to find patterns or links which

46 show the connections and interactions between natural disasters. The study will look

47 particularly at events recorded in Japan since Japan is one of the most natural hazard prone

48 countries in the world and therefore many records of natural disasters and their consequences

49 have been recorded there. These records serve as histories in which citizens went through

50 hardships, as warnings for preparation and as lessons which should be learned. These records

51 are considered very useful resources to create a holistic picture of how primary natural

52 hazards can trigger secondary hazards.

53 It should be noted that the linkages and relationships in cascading natural hazards found in

54 this study may not be directly applicable to other countries, or to regions with different

55 geographical and meteorological features since the occurrence of natural disasters depends on

56 the local conditions. For instance, earthquakes are rarely experienced in areas on stable

57 tectonic settings while Japan experiences earthquakes frequently. On the other hand, wild

58 fires are less of a problem in Japan but are more of a problem in Australia, USA and Russia.

59 Again, floods in Japan tend to be shorter lasting, fast flowing flash floods, whereas elsewhere,

60 such as in Thailand (Aon Corporation 2012), there may be deepwater floods which are longer

61 lasting (Nagai et.al. 2010). Thus the earth shows a wide variety of geographical and

62 meteorological features, and natural hazards can occur in a different manner and with

63 different frequency depending on the area. However, studying the features found in Japan

64 should contribute to an initial understanding of cascading natural disasters and help establish

65 an effective system for intervention.

66 In the next section the relevant literature on natural disasters will be reviewed and this is

67 followed by a section explaining how the data for this study was collected and analysed from

68 Japanese sources. The analysis of the data leads to the identification of four modes of links

69 or interactions which are presented and explained in the following section, while the final

70 section presents some concluding remarks. 
79 The literature survey found that many existing studies about cascade/domino disasters belong

80 to the domain of the chemical processing industries (Abdolhamidzadeh 2011). Some

81 academic studies have dealt with problems spreading through elements or units physically

82

83 connected to each other such as infrastructure systems (Harper 2007) and logistic networks (Brimer 1995). Significant attention has also been paid to the propagation of phenomena through financial, political or health systems, or various types of communities. These studies have focussed on the vulnerabilities of the entities in question, transition features, and their consequences, and seek to analyse the phenomena, so that lessons may be learnt to prevent recurrence and to establish intervention strategies.

In those studies, a natural hazard is seen as a triggering event which is the initiator or the initial condition which sets off a chain of damaging events in industrial situations, social systems, and so on, but is not considered as a natural event which leads or causes one or more other damaging natural events so leading to cascading natural disasters. These studies clearly present the significance of disasters caused by natural hazards and note the ensuing continuous efforts to mitigate the losses. The information for assessing estimates of likelihood, severity of hazards, vulnerability data are indispensable for setting up a proper mitigation system (Hamiltom 2000). But they varies with the types of hazard because specific vulnerability depends on the hazard providing an impact. Since for a single natural hazard the vulnerabilities, the sequence of events following, and the mitigation measures can differ from one natural hazard to another, the independent method treatment of a single hazard cannot always cope with multiple natural hazards. The overall risks are not just the sum of single individual risk analyses. The characteristic features, analysis methods and the influence of

101 each hazard are different, and multiple hazards can compound impacts from single hazards by 102 mutual interaction and interrelation.

103 In 2010, the European Commission adopted the Commission Communication on "an all104 hazards approach to threat and risk assessment” based on a multi-hazard and multi-risk 105 approach for disaster management (European Commission 2010). They noted multi-hazard or multi-risk situations should to be considered in the risk identification which should consider all possible hazards, their probabilities of occurrence and their possible impacts. Multi-risk assessments in this context means determining the total risk from several hazards. There are two types: First, those occurring at the same time or following shortly after each other, because they are dependent on one another or because they are caused by the same triggering event or hazard. Second, those threatening the same elements without chronological coincidence. Those in the first type are referred to as domino effects or cascading events. An expert group established by the OECD analysed the current problem of multi-hazard risk modelling (OECD 2012). Their survey resulted in some findings, such as strong demand for 115 data mining and standards, lack of matured multi-risk/multi-hazard assessment models, and 116 rarity of consideration of potential cascading/domino effects in natural-man-made systems.

117 As an effort to establish a methodology which combines multiple risks, integrated multi-risk 118 maps were developed to assist spatial planning procedures in areas prone to natural disasters 
119 in AROMNIA (Applied multi Risk Mapping of Natural Hazard for Impact Assessment)

120 project (AROMNIA project, 2007). The project produced a risk index for a particular hazard

121 by combining the consequences on different receptors. The NaRAs (Natural Risk

122 Assessment) project aimed at producing a quantitative estimation of individual and coupled

123 events based on the concept of a Bayesian event Tree (Marzocchi 2009). Scenarios composed

124 of a few hazardous events were quantified. They concluded that the probability of a single

125 risk was underestimated while the probability incorporating other types of risk showed

126 greater magnitude (Marzocchi 2012). Schmidt et.al. prepared a prototype software for

127 assessing the risk due to a generic natural hazard. The system is capable of calculating risks

128 for different types of hazard but, the system does not permit modelling the interactions

129 among multiple hazards (Schmidt 2011). Mignan et.al. describe a probabilistic approach or

130 Monte Carlo Method aimed at providing numerical data to compare risks from different

131 origins (Mignan 2014). Despite these efforts, Kreibich et.al., reported German cases and

132 found that the present event and risk analyses, as well as risk management, focussed on only

133 one single hazard, and did not consider conjoint or cascading events on an interrelated multi-

134 hazard basis approach (Kreibich 2014). Kappes et. al. emphasized the necessity of

135 considering a whole range of natural hazards and their management from the viewpoint that

136 all potential threats should be taken into account for risk management (Kappes 2012). The

137 possible interaction among cascading effects has yet to be fully understood, represented, and

138 fully integrated in risk assessment.

139 This literature survey has shown that the interacting features of different hazards and their

140 cascading effect has been less studied than expected in the light of its importance. Some

141 examples of cascading natural effect are known to researchers and those communities which

142 have been historically affected. For example, studies on earthquakes leading to landslides are

143 found in various journals (Miles 2011; Rodri'gueza 1999; Pearce 1986; Meunier 2008; Ju-

144 Jiang 2000). Xu et al., point out that there is a chain of natural hazards in most catastrophic

145 disasters and introduce Chinese literature on geological, meteorological, and geological-

146 meteorological hazard chains (Xu 2014). However, the knowledge is not systematic and is

147 dispersed. Research methods have been established for each hazard, but there is no overall

148 perspective for the whole range of natural hazards due to the separation of disciplines.

Data Collection Methodology

151 In this research, the interactions between individual natural events leading to disasters are

152 investigated and the cascading phenomena which emerge are categorised. One of the

153 challenges in starting this research was to find good sources of information. In most available

154 research databases, natural disasters are recorded as single independent events, making it

155 difficult to investigate any relationships connecting these natural hazards. Moreover, as many

156 researchers have pointed out, the lack of internationally standardised reporting and record

157 keeping is a major hindrance (Krausmann 2008; Wirtz 2014). So, it is not possible to find a

158 reliable scientific record of linked natural events leading to disasters 
159 To overcome this problem this study focused exclusively on Japanese cases. Since the study

160 focussed on the interactions between natural events there is no need to investigate each

161 natural disaster in detail. Instead the focus is on the linkages between different disasters

162 using a qualitative approach. Since there are few previous studies of cascading, it is worth

163 trying to compile data on observed cascading natural hazards.

164 For this study, the Kikuzo II Visual for Libraries was chosen as the main source of

165 information. It is an online commercial database provided by the Japanese newspaper Asahi

166 Shimbun. Asahi Shimbun was first published on 25 January 1879 in Osaka and now has a

167 domestic news gathering network organised by 4 head offices and 2 offices and a global news

168 gathering network consisting of 34 bureaus (The Asahi Shimbun 2012). In October 2014, its

169 circulation was about 7 million for the morning edition and 2.3 million for the evening

170 edition (The Shimbun Joho 2014). The database contains full text coverage from 1985 to

171 present, as well as articles from AERA and Shukan Asahi which are weekly magazines

172 published by a subsidiary of Asashi Shimbun. The image data or pdf files of articles for

173 earlier years, going back to 1876, are also contained in the database, but this study did not use

174 these since text search is not applicable to this data. Clearly this approach excludes the

175 consideration of events that were not reported in the newspaper. It also limits the depth of

176 understanding of these events, since the newspaper reports can be influenced by speculation

177 about the cause of disasters which had not been fully determined at the time the article was

178 published. To overcome these shortcomings, the study also drew on formal documents and

179 online resources and utilised research reports from research institutes and articles in

180 domestic/international academic journals to establish that it is likely that a causal relationship

181 exists between the apparently cascading events under consideration. In addition some related

182 in-depth articles were studied to gain a better understanding of the occurrences and the causes

183 of the events.

184 Data was retrieved from the Kikuzo II Visual for Libraries using the search system provided

185 in the database. The key words used for searching were combinations of a few words

186 meaning "countermeasure" or "damage”, and the name for each natural hazard event in the

187 Japanese language. The number of hits for each such natural event is summarised in Table 1.

188 The articles found included various types of information such as death toll, interviews with

189 victims, physical and economic damage, the response of the affected local community, etc.

190 In total the search generated 94,228 articles which were skimmed for relevance. Some

191 natural disasters were described multiple times and in more than one location from various

192 aspects because they had wide spread and long-term effects. Some records found in the

193 search had nothing to do with actual natural hazards. In such records, a natural hazard

194 appears as a metaphor for some other aspect of life. Since this study was focussing on

195 cascading natural disasters, all the other records were read and suitable ones were selected to

196 consider the linkages and interactions between the natural events.

197 Some keywords in table 1 consist of more than one search term. For example, two Japanese

198 search words Yamakaji (fire in mountain) and Shinrin Kasai (fire in forest) are included in

199 wildfire. Needless to say, there are some overlaps in each set of search results because some

200 of the articles relate to cascading natural disasters. For instance, some articles describing 
earthquakes also mentioned tsunami. Therefore the sum of the number of all the search results does not match the net number of individual articles reviewed. When a search was conducted, options were utilised to exclude other keywords for time reduction. Despite this effort, there still remained a large number of articles for each natural event. All the articles were carefully read and inappropriate articles removed. For the remaining articles, when the article writer clearly mentioned or implied a linkage, the article was read to look for linkages between the hazards described in the article, and then reread to avoid missing valuable information. As noted before, the linkage mentioned in each article can involve speculation. However, most of those writing these articles have previous experience to draw on and often interview local people about their historical knowledge and experience. Also, the articles had to include two or more natural phenomena occurring in a reasonably short time frame, allowing the researchers to suspect there was a connection between the phenomena rather than these being just two or more individual unrelated phenomena. We consider that these criteria combined together were be enough for the first stage process to filter out inadequate information prior to checking with academic papers, research reports, or other resources providing scientific researches.

Table 1 The keywords and the number of articles

\begin{tabular}{llll}
\hline \hline Geological & & & \\
\hline Earthquake & 46290 & Volcanic eruption & 5284 \\
Land Slide/Collapse & 21045 & & \\
\hline Meteorological & & & \\
\hline Hurricane & 1712 & Heavy rain & 12081 \\
Heat wave & 6678 & Heavy snow & 5866 \\
Lightning & 1156 & Strong wind & 5792 \\
\hline Hydrological & & & \\
\hline Tsunami & 21219 & Flood & 7723 \\
High tide & 2089 & & \\
\hline Other & & & \\
\hline Wild fire & 804 & & \\
\hline \hline
\end{tabular}

219 The extent to which a complicated or compound natural event can be divided into separate 220 elements needs to be considered. In this study, any event which can cause some physical 221 destruction is regarded as a relevant fundamental event. For instance, some natural 222 phenomena involve more than one element; a typhoon can involve extreme winds, heavy 223 precipitation, and storm surges. A typhoon is a combined phenomenon of elements which are 224 caused by low pressure. This study deals with the fundamental events rather than the 225 compound event since each fundamental event itself can cause disastrous consequences. As 226 another example, volcanic activities involve many processes and can be considered as 227 comprehensive phenomenon. Volcanic activity is directly related to plate tectonics and 228 produces magma, which is molten rock. It penetrates through crust because of the gas 229 pressure dissolved in it. Volcanic activity is associated with one or more of the following 230 phenomena: lava effusion, ash and ejection of pyroclastic rocks, poisonous gas release, 231 shockwave and seismic tremolo (Johnson 2011; Miyabuchi 2013). Debris flows, mudflows 
232 and other mass movements are categorised as secondary effects in some text books (Keller

233 and DeVecchio 2012). Although each process has links to other processes, this study does not

234 seek them in-depth. The interest of this study lies in the connections between different types

235 of events each of which itself can be a cause of physical destruction.

236 Since this research was focussing on cascading natural disasters causing physical destruction,

237 events leading only to the disruption of social systems and biological issues were omitted.

238 Chapman wrote that natural hazards might be defined as an interaction between a system of

239 human resource management and an extreme or rare natural phenomenon which may be

240 geophysical, atmospheric or biological in origin (Chapman 1994). Since such a natural hazard

241 can have massive impact, consequential events can arise in various areas and, in particular

242 can cause disruption to various systems developed by humans. For instance, massive physical

243 impacts caused by natural hazards can destroy systems for maintaining public health and

244 hygiene. The event itself can also push human beings towards a serious crisis. When we add

245 biological threats into our scope, natural hazards affecting critical infrastructure would be

246 listed because infrastructure plays a major role in maintaining public hygiene. However,

247 such hazards are not within the scope of this study. On the other hand, natural phenomena

248 interacting with each other and showing massive power to cause physical destruction can be

249 described as a natural disaster in this research even though no harm is caused to the human

250 habitat; maybe due to the large distance of the events from any human habitat.

251 Many natural events can trigger technological accidents: volcanic ash can cause clogging in

252 filters or pipes in critical infrastructure (Wilson et al. 2010). Snow makes railway lines

253 slippery causing derailment (Zhou 2013). However, these events do not cause any further

254 natural disasters so are excluded from the current definition of cascading natural disasters.

255 Similarly some cascading natural disasters are phenomena involving highly destructive and

256 wide ranging events but we limit our scope to only the physical aspects of these natural

257 disasters.

Data Analysis Methodology

260 After selecting the appropriate and relevant articles containing descriptions of cascading

261 natural hazards, we used the Grounded Theory approach to conduct our analysis (Corbin and

262 Strauss 1990). A growth in the use of the Grounded Theory approach has been seen in recent

263 years as a qualitative research method. The Grounded Theory approach uses a set of data

264 collection and analysis procedures to develop inductively derived theories, concepts, patterns, 265 and categorises from data (Eaves 2001). In the Grounded theory approach, data collection 266 and analysis are interrelated and the analysis begins as soon as the data is collected. This is a 267 central feature of the approach and is often referred to as the constant comparative method.

268 The Grounded theory approach allows a researcher to identify patterns, and relationships 269 between these patterns. The Grounded Theory approach in this study was applied to identify 270 relationships between the natural events and develop higher-abstraction level type categories 271 of cascading natural disasters. 
272 Grounded Theory techniques were used to identify categories as they emerged from the data

273 (Reddya et al. 2009). Concepts that are common to several phenomena may be grouped to

274 form categories. In the analysis process, we read the article carefully, extracted data of

275 natural events comprising cascading phenomena. We mapped individual events and the

276 linkages between events. Each causal relationship in the linkage was verified to test if it was

277 plausible by examining other scientific resource such as academic journals and technical

278 reports open to public. Then, as concepts start to appear in our mind that captures properties

279 of the data, we consider the nature of each event and linkages carefully. This process aims at

280 conceptualising and articulating the set of linkages. For example, snow appears to work as

281 storage of potential energy when it starts an avalanche. This gave the concept "depositing” at

282 first, since accumulated snow increases the risk of the following phenomenon. However,

283 during the process of conceptualisation, it became apparent that this relationship could be

284 included in "undermining" which is a higher-order conceptualization. The study continued

285 until the conceptualization became "saturated”, meaning no new data or linkages appear and

286 all the linkage could be included in the conceptualization. The final core categories (called

287 modes in this study) that emerged from the data are presented here.

288 Results and Discussion

289 In this section the main features of cascading natural disasters are analysed and the

290 relationships that emerged are presented in a series of figures (Fig. 1).

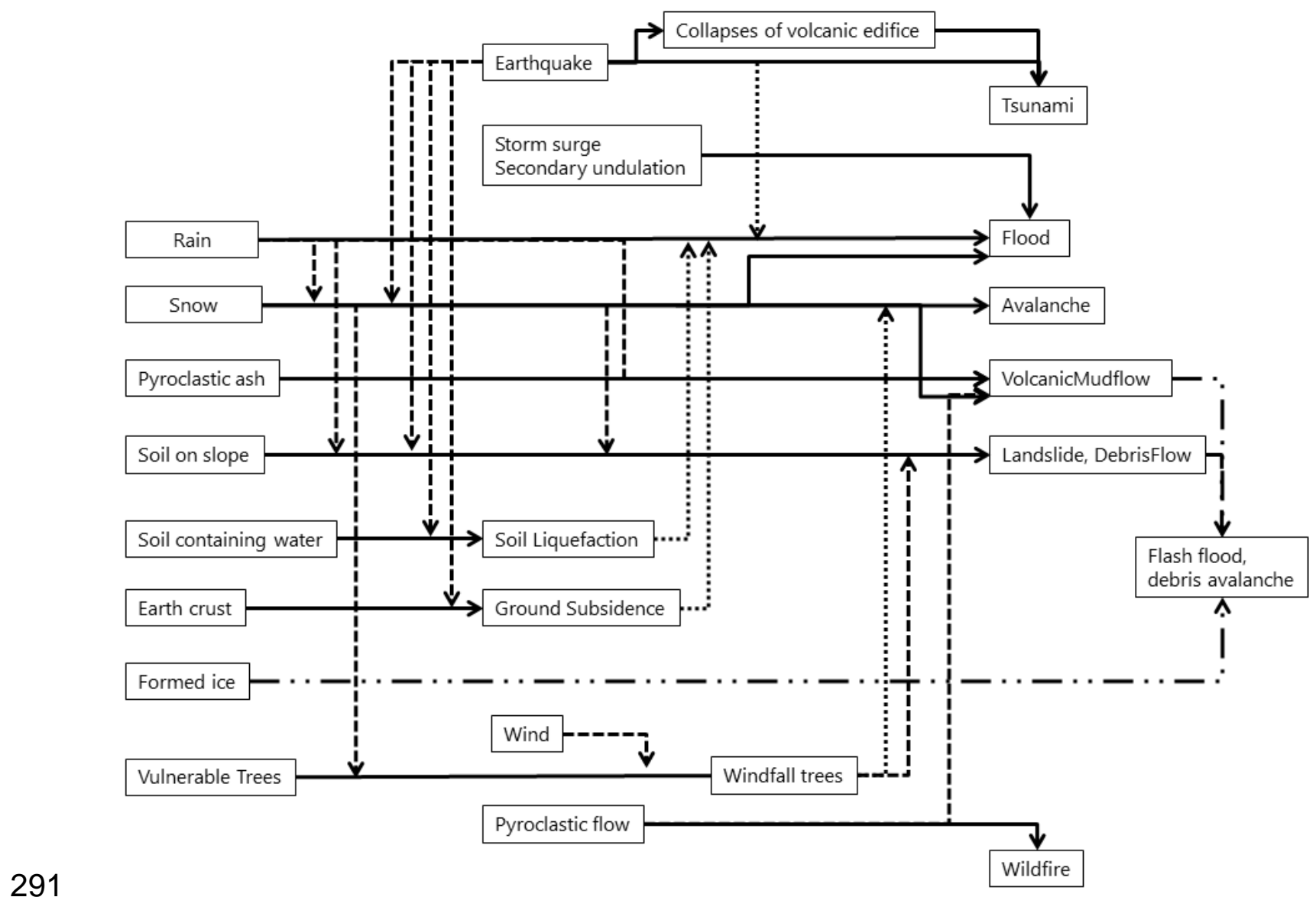

Fig. 1 Relationships of cascading natural hazards 
293 The relationships emerged from considering cascading natural disaster appeared in articles up

294 to October 2014. As many sources as possible were considered so that few, if any, relevant 295 incidents are missing. The figures may not include all the cascading effects that have

296 occurred in Japan, but we believe all the significant ones are included.

297 Some common natural disasters are not included in the figures because they were not found

298 in the database as either a trigger or a result of any cascading natural disaster, although by 299 themselves each can be harmful and destructive. For instance, the shockwave produced in a 300 volcanic eruption can break nearby windows (Kato and Yamasato 2013), but the searches 301 conducted found no data in the database to indicate that it was triggered by or occurred with 302 another natural hazard. As another example, lightning is known to cause fires or secondary 303 effects such as bound charge, electromagnetic pulse, electrostatic pulse, and earth currents 304 (Changa and Lin 2006). But it does not usually cause a widespread wildfire or any other 305 natural disaster.

306 The interaction between natural disasters can be divided into four patterns, or modes. In the 307 following section, the numbers in each figure indicate the count of cases appearing in articles. 308 Some cases are latest news coverage at that time and others are historical disasters discussed 309 so that lessons can be learned.

310 "Striking" Mode; in this mode a primary disaster has significant further physical impact by 311 imparting sufficient energy to move a significant mass or to propagate the energy through 312 media which can then cause significant destruction during the process. The moving mass and 313 propagating energy are secondary natural hazards and sources of destruction in addition to 314 the initial primary hazard (Fig. 2). 


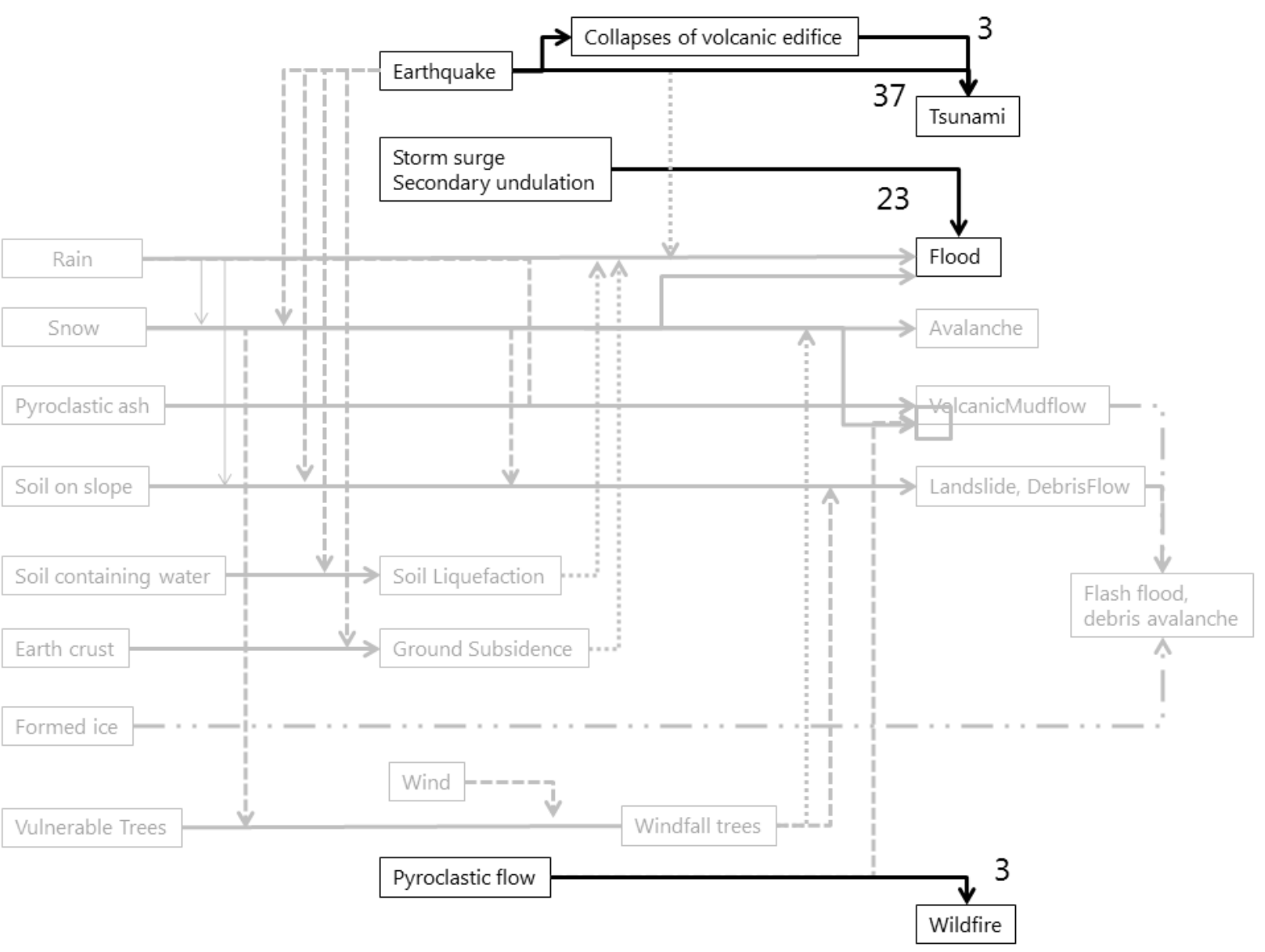

Fig. 2 Cascading natural disasters categorised as “Striking” mode

317 This mode includes the cases of cascading natural disasters caused by the power of geological

318 and meteorological phenomena. Enormous amounts of energy are released by the initial

319 event which is then transmitted through some mass, or transports some mass.

320 The major events constituting the primary disaster for this mode are: earthquakes, collapses

321 of volcanic edifice, storm surges and secondary undulations, and the secondary hazards are

322 tsunami, and flood.

323 When the seismic power imparts energy to sea water through movement of the sea floor, the 324 secondary event is a tsunami (Nirupama 2013). Even an earthquake with a relatively small 325 magnitude can generate large and widespread tsunamis (Kanamori 1972). Initially the 326 tsunami wave moves rapidly in the deep ocean, but it slows down as the depth decreases and 327 the height of water increases as it reaches the coast. The height of the tsunami at landfall 328 directly affects the scale of the resulting damage.

329 Other events which provide impact energy to elevate the sea surface are storm surges 330 (Nirupama 2013) and secondary undulation (Honda et al. 1908). Although tsunamis 331 propagate through deep oceans, storm surges do not exist in the deeper part of the oceans but 332 are found in shallower ocean areas and are caused by meteorological phenomena. Secondary 333 undulation (one kind of seiche), is also a meteorological phenomenon which has been found 334 in harbours (Hibiya and Kajiura 1982). Atmospheric-pressure variation cause these long 
335 waves with extraordinary amplitudes which can reach $1.5 \mathrm{~m}$. Secondary undulation results

336 when long waves come into a harbour with amplitudes close to the natural modes of

337 oscillation of the harbour (Kakinuma and Fukita 2011). The subsequent strong currents

338 caused by a secondary undulation in 2009 caused floods and severe damage to cargo-vessels,

339 fish reserves, banks and so forth (Kakinuma et al. 2009). Another natural event inducing

340 transportation of mass and causing a secondary effect is the collapse of a mountain hill side

341 (collapses of volcanic edifice). In 1792, Mt. Mayuyama collapsed following earthquakes

342 generated by volcanic activity and a large section of the mountain fell into Ariake Sea

343 (Kawamata et al. 2005). This shock induced a tsunami and the death toll is said to be about

344 15000. So, this incident involved three consecutive disasters: first, the earthquakes as a

345 primary effect, second, the hill side collapse as a secondary effect, and third, the tsunami as a

346 tertiary effect. These three events comprised the cascading natural disasters.

347 An example of energy propagating through media is thermal energy which can cause a

348 wildfire. Wildfires are frequently reported as damage resulting from a volcanic eruption

349 (Annen and Wagner 2003). Since high temperature magma dominates volcanic activity, its

350 products, lava, pyroclastic surge and flow, supply heat to set fire to surrounding forests.

351 Wildfires following volcanic eruption were observed at Mt. Asama, September 2004, Mt.

352 Unzen, May 1993, June 1991, Mt. Mihara, November 1986 and in several earlier events.

354 “Undermining” Mode; in this mode of the linkage, a primary disaster lowers the resistance or 355 weakens a system maintaining mass and the mass ends up collapsing (Fig. 3). 


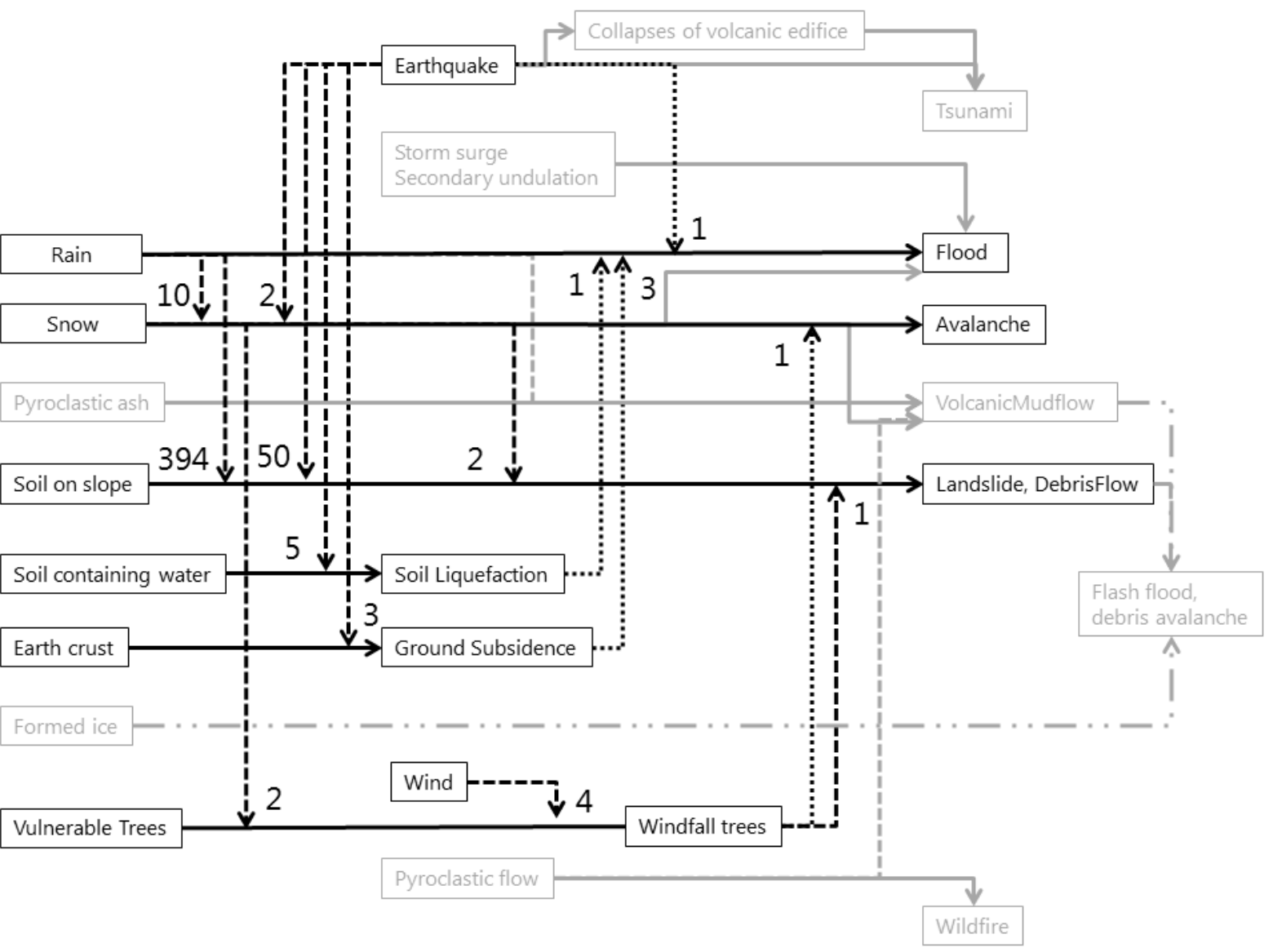

Fig. 3 Cascading natural disasters categorised as “Undermining” Mode.

358 There are various systems which support or retain mass. The natural events in this mode reduce the strength or the capacity of such a system, or make such a system fragile. The system can be artificial. An example is an earthquake which occurred in Nara in 1854 which caused a reservoir to collapse and the water released caused a flood. Similarly earthquakes can damage river banks or sea walls which are structures to support and channel streams of water.

The system affected by “undermining” can be natural. In the natural system, internal forces, such as friction, connect elements and can help retain mass stability on a steep surface. Such forces help maintain the stability of soil or snow because the force keeps each particle together. The mass of soil or snow will distort and may be displaced when an external strong force is applied. Similarly, when the natural hazard applies a greater force to the system than the retaining force, such a system will become unstable.

In the figure, deposited systems are placed on the left side. Broken lines indicate the natural hazards action to perturb the "deposited" system shown on the left side in figure. The natural hazards affect the internal forces within the deposited system. Dotted lines represent the natural hazards action in reducing the strength or capability of supporting or reinforcing 374 system to maintain the mass. For example, accumulated snow can result in avalanche from 375 rain (indicated with a broken line, Stimberis and Rubin 2011) or earthquake (Podolskiy et al. 2010) by breaking the connection between grains or chunk of snow, while strong winds 
377 upturning trees increases the risk of an avalanche because the trees function to stabilise the 378 snow cover (Bebi et al. 2009). In the same vein, a landslide can be caused by rain (Inverson 379 2000, Montrasio and Valentino 2008) or earthquake. Both of them disturb the forces 380 maintaining soil reinforcement. The most common landslides following an earthquake are shallow disrupted landslides on steep slopes, but the Mid Niigta prefecture earthquake in 2004 triggered more than one hundred deep landslides (Chigira and Yagi 2006). Damage to tree roots by strong winds contributed to reducing soil reinforcement and shear strength as well (Abe and Ziemer 1991, Afforestation and Forestry-Road Association of Hyogo 2008.). In this case, the link from "windfall trees" is represented as a broken line. In another example, there were landslides linked to the problem of trees destroyed by several typhoons in Hyogo, Japan 2004. Several typhoons struck the area in that year and trees were uprooted by the typhoon on 19 October which was not the strongest typhoon. Thus, the subsequent landslide was considered to occur because of significant damage to trees by the preceding typhoons in the year. It is argued that the ground support system had been reduced by the tree damage of the earlier typhoons. When trees are expected to act as protective system to mitigate avalanches, wind damage to trees is a severe problem.

393

Another example is ground subsidence. Ground subsidence per se is a problem when it lowers the ground unevenly. Facilities on the uneven ground can lean dangerously or fall. The subsistence caused by an earthquake or pumping water out from the ground can also cause a secondary natural hazard. For example, the earthquake in Japan, 2011 led to ground subsidence in a wide area. Oga moved by about $5.3 \mathrm{~m}$ horizontally and was lowered by about $1.2 \mathrm{~m}$ (Geospatial Information Authority of Japan). The phenomena made the affected area more vulnerable to flood or tsunami (Udo et al. 2012).

Another example of this type of undermining is soil liquefaction which can be found in some landfill sites after an earthquake. An earthquake shakes the soil, loosens the connections between the soil particles and causes water distributed in the soil to rise up to the surface. The ground in the area becomes a suspension and the soil particles eventually settle under water (Fiegel and Kutter 1994). This situation arose in the wake of the earthquake in 1964 Niigata and Alaska (Seed 2003). Solid liquefaction can be a severe problem particularly if there are 407 lean and fall down.

408 In this first sense, soil liquefaction is a secondary natural hazard caused by an earthquake. It can also be seen as a primary natural hazard in the "undermining" mode. As mentioned above, water trapped in soil is released as soil liquefaction and inundated the affected area for 7

411 hours. (Tohno and Shamoto 1986). By another mechanism, it can also reduce the strength of 412 the foundations of critical infrastructures such as river banks or walls (Yoshitake 1992), so in 413 the face of a natural disaster these facilities are no longer capable of preventing a flood, a 414 secondary natural disaster.

415 This mode is characterized by some event reducing the capability of a system to support mass, 416 and so the resulting system failure maybe preceded by a process which deposits and builds up 417 mass. 
419 "Compounding” Mode: in this mode of the linkage, a primary disaster reduces the strength of 420 a system and adds to the amount of mass affected (Fig. 4).

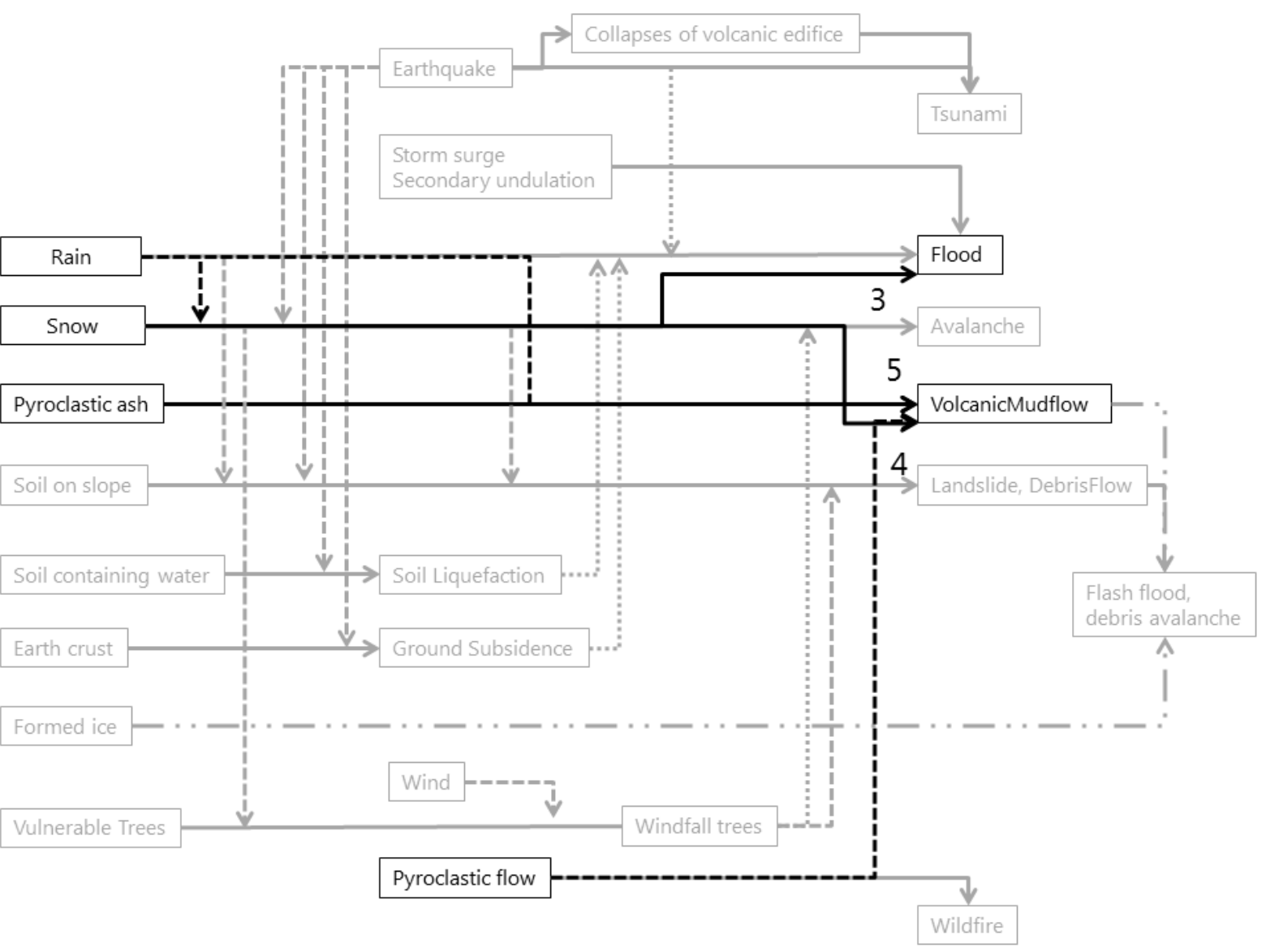

Fig. 4 Cascading natural disasters categorised as "Compounding”. Dotted lines indicate the primary natural hazards action to perturb the system and increase mass affected.

424 A primary event categorized as a compounding itself causes a disaster. Moreover, the impact 425 of the primary event increases when it interacts with a deposited mass. For instance, the 426 impact of the pyroclastic flow significantly increases when it contacts deposited snow and the 427 resulting increased volume of fluid magnifies the problems as volcanic mudflow (Waitt et 428 al.1983). Pyroclastic ash is also a product of volcanic activity and can be deposited on the 429 affected area. If it then rains on the ash, the mixture of ash and rain leads to a mud flow 430 (Young et al. 1998). Snow thaws as the temperature rises and heavy rain in that season can 431 cause a rapid thaw leading to floods (Sui and Koehler 2001). The combination of snow and 432 rain is also found in undermining mode, but this case results in a flood rather than an 433 avalanche.

435 Blocking: in this mode of the linkage, an event blocks steady flows (Fig. 5). 


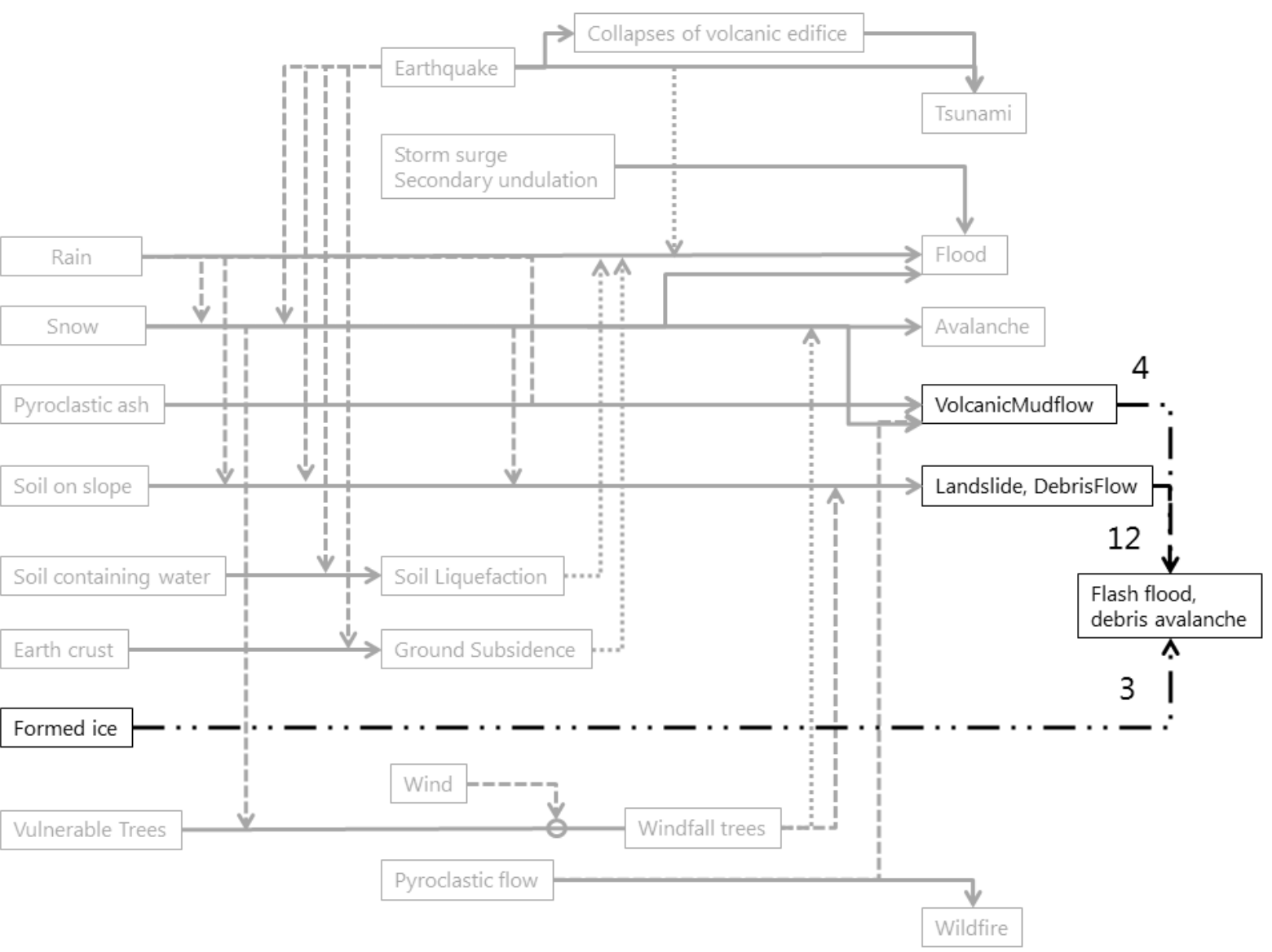

Fig. 5 Cascading natural disasters categorised as “Blocking” Mode

438 In this mode, a mass collapses and blocks a river causing a hazardous situation which can result in flooding upstream or a sudden break of the barrier and a flash flood downstream.

440 Volcanic mudflow, landslide and debris flow can create a dam by falling into a river (Costa and Schuster 1988). A river can be clogged by partially melted ice which is known as an "ice jam” (Beltaos and Prowse 2001; Hirayama et al. 2002). In this mode the risk of the secondary event takes time to increase as sufficient mass has to accumulate either to flood upstream or cause problems downstream beyond the temporary blockade.

445 Edward Bryant discusses hazards in environmental studies in terms of two timeframes. One 446 is chronic which refers to long term and slowly developing hazards such as desertification or 447 soil degradation that may be caused by human activity or by global warming. The second 448 time frame is called episodic or periodic. This second timeframe considers people as living 449 within a hostile environment over which they have no control. These sorts of hazards are 450 large magnitude events that last for a short period of time like an earthquake (Bryant 2006). 451 These ideas suggest that for cascading natural disasters it is important to incorporate the idea 452 of a time frame for natural events, and, in particular, allow for time delays between the 453 primary and secondary events. Especially in the case of the blocking mode, it is important to 454 note that whilst the primary event can result in significant destruction itself it can, by 455 blocking a flow, cause a secondary disaster to build up gradually over a longer period of time 456 than is normally thought of in cascading natural disasters. 
Concluding remarks

459 The linkages between natural disasters in cascading natural disasters have been presented and 460 discussed in this paper. The results are based on reviews of nearly 100,000 newspaper articles 461 reporting damage and loss caused by natural disasters in Japan. Attempts were made to 462 explain the links between these natural disasters and this led to the identification and 463 definition of several modes to categorise different types of linkage connecting the natural 464 disasters which form part of a cascading natural disaster.

465 Four modes of interaction emerged from the investigation. The mode termed "Striking" 466 occurs when a primary natural event imparts sufficient energy to transport a large mass of 467 water or solid material or to transmit energy through media. These phenomena are regarded 468 as secondary natural disasters and cause disruption additional to the primary disaster. The 469 mode termed "Undermining” represents cases where a primary natural event damages the 470 sustaining system of some mass, which may then disintegrate causing a secondary disaster. 471 The third mode is termed "Compounding” and occurs when a primary event interacts with a 472 sustaining system of mass, damaging the system and merging itself into the mass to create a 473 greater secondary disaster. The mode termed "Blocking” represents a pattern in which a mass 474 in motion blocks an existing flow of water temporarily until the increased mass bursts or 475 overflows the obstruction leading to a flash flow of water and debris down steam.

476 This collation and categorisation of cascading natural disasters has led to a greater 477 understanding of their nature. The results are important for an understanding of the impact of 478 these types of cascading natural disaster and so are valuable as a basis for the identification, 479 description, and development of countermeasures. The results will be beneficial for personnel 480 considering overall risk management by providing them with a better perspective on 481 cascading natural disasters.

482

483 Reference List

484 Abe K, Ziemer RR (1991) Effect of tree roots on a shear zone: modeling reinforced shear 485 stress. Canadian Journal of Forest Research, 1991, 21(7): 1012-1019

486 Abdolhamidzadeh B, Abbasi T, Rashtchian D, Abbasi SA (2011) Domino effect in process 487 industry accidents - an inventory of past events and identification of some patterns. Journal 488 of Loss Prevention in the Process Industries. 24:575-593

489 Afforestation and Forestry-Road Association of Hyogo (2008) The damage of windfall trees 490 by typhoon 2004, and measures for consequences.

491 http://www.chisanrindou.net/data/pdf/books/book12.pdf. Accessed 25 March 2015

492 Annen C, Wagner J-J(2003) The Impact of Volcanic Eruptions During the 1990s. Nat.

493 Hazards Rev. 4:169-175. 
494 Aon Corporation (2012) Thailand Floods Event Recap Report, Impact Forecasting - March

4952012.

496 http://thoughtleadership.aonbenfield.com/Documents/20120314_impact_forecasting_thailand

497 _flood_event_recap.pdf. Accessed 25 March 2015

498 The applied multi-risk mapping of natural hazards for impact assessment (ARMONIA)

499 project (2007)

500 http://ec.europa.eu/research/environment/pdf/publications/fp6/natural_hazards/armonia.pdf

501 The Asahi Shimbun, Corporate Report 2012

502 http://www.asahi.com/shimbun/company/2012.pdf. Accessed 25 March 2015

503 Bebi P, Kulakowski D, Rixen C (2009) Snow avalanche disturbances in forest ecosystems-

504 State of research and implications for management. Forest Ecology and Management.

505 257:1883-1892

506 Beltaos S, Prowse TD (2001) Climate impacts on extreme ice-jam events in Canadian rivers.

507 Hydrological Sciences Journal. 46:1:157-181

508 Bertman S (2003) Handbook to Life in Ancient Mesopotamia. Oxford University Press, p204

509 Brimer RC (1995) Logistics networking. Logistics Information Management. 8:4:8 - 11

510 Bryant E (2006) Natural Hazard, Cambridge University Press, Australia, p1

511 Changa JI, Lin C-C (2006) A study of storage tank accidents, Journal of Loss Prevention in

512 the Process Industries. 19:51-59

513 Chapman D (1994) Natural Hazards. Oxford university press

514 Chigira M, Yagi M (2006) Geological and geomorphological characteristics of landslides

515 triggered by the 2004 Mid Niigta prefecture earthquake in Japan. Engineering Geology.

516 82:202- 221

517 Corbin J, Strauss A (1990) Grounded Theory Research: Procedures, Canons, and Evaluative

518 Criteria, Qualitative Sociology, 13:1:3-21

519 Costa JE, Schuster RL (1988) The formation and failure of natural dams. Geological Society 520 of America Bulletin. 100:7:1054-1068

521 Eaves YD (2001) A synthesis technique for grounded theory data analysis. Journal of 522 Advanced Nursing 35:654-663

523 European Commission (2010) Commission staff working paper: Risk assessment and

524 mapping guidelines for disaster management. Brussels, December

525 http://ec.europa.eu/echo/files/about/COMM_PDF_SEC_2010_1626_F_staff_working_docum 526 ent_en.pdf 
527 Fiegel GL, Kutter BL (1994) Liquefaction Mechanism for Layered Soils. J. Geotech. Engrg. 528 120:737-755.

529 Geospatial Information Authority of Japan.

530 http://www.gsi.go.jp/chibankansi/chikakukansi40005.html Accessed 25 March 2015

531 Hamilton RM (2000) Science and Technology for Natural Disaster Reduction. NATURAL

532 HAZARDS REVIEW / FEBRUARY pp.56-60

533 Harper MA, Thornton MA, Szygenda SA (2007) Disaster Tolerant Systems Engineering for

534 Critical Infrastructure Protection, Systems Conference, 1st Annual IEEE, Honolulu, HI, (9-13

535 April 2007) pp.1-7

536 Hibiya T, Kajiura K (1982) Origin of the Abiki Phenomenon (a Kind of Seiehe) in Nagasaki 537 Bay. Journal of the Ceanographical Society of Japan. 38:172-182

538 Hirayama K, Yamazaki M, Shen HT (2002) Aspects of river ice hydrology in Japan.

539 HYDROLOGICAL PROCESSES, 16:891-904

540 Honda K, Terada T, Yoshida Y, Isitani D (1908) Secondary Undulations of Oceanic Tides.

541 Journal of the College of Science Imperial University Tokyo, Japan. 24:1-113

542 Inverson RM (2000) Landslide triggering by rain infiltration. Water Resources Research.

$543 \quad 36: 7: 1897-1910$

544 Johnson JB, Ripepe M (2011) Volcano infrasound: A review. Journal of Volcanology and

545 Geothermal Research. 206:61-69

546 Ju-Jiang H (2000) Chi-Chi Earthquake Induced Landslides in Taiwan. Earthquake

547 Engineering and Engineering Seismology. 2:25-33

548 Kakinuma T, Asano T, Inoue T, Yamashiro T, Yasuda K (2009) Survey on February 2009

549 Abiki Disaster in Urauchi Bay, Kamikoshiki Island. Journal of JSCE B2 (Harbour

550 engineering). B2-65:1:1391-1395

551 Kakinuma T, Fukita K (2011) A Numerical Study on Long-Wave Generation and 552 Propagation due to Atmospheric-Pressure Variation. Journal of JSCE B2(Harbour 553 engineering) 67:2:156-160

554 Kanamori H (1972) Mechanism of tsunami earthquakes. Physics of the Earth and Planetary 555 Interiors. 6:5:346-359

556 Kappes MS, Keiler M, Elverfeldt KV, Glade T (2012) Challenges of analyzing multi-hazard 557 risk: a review. Nat Hazards 64:1925-1958

558 Kato K, Yamasato H (2013) The 2011 eruptive activity of Shinmoedake volcano,

559 Kirishimayama, Kyushu, Japan -Overview of activity and Volcanic Alert Level of the Japan 560 Meteorological Agency-. Earth Planets Space. 65:489-504 
561 Kawamata K, Takaoka K, Ban K, Imamura F, Yamaki S, Kobayashi E (2005) Model of

562 Tsunami Generation by Collapse of Volcanic Eruption: The 1741 Oshima-Oshima Tsunami.

563 Tsunamis Advances in Natural and Technological Hazards Research. 23:79-96

564 Keller EA, DeVecchio DE (2012) Natural Hazards, 3rd ed. Pearson Education, Inc. New

565 Jersey, pp143-145

566 Krausmann E, Cruz AM (2013) Impact of the 11 March 2011, Great East Japan earthquake

567 and tsunami on the chemical industry. Nat Hazards 67:811-828

568 Krausmann E, Mushtaq F (2008) A qualitative Natech damage scale for the impact of floods 569 on selected industrial facilities. Natural Hazards. 46:179-197

570 Kreibich H, Bubeck P, Kunz M, Mahlke H, Parolai S, Khazai B, Daniell J, Lakes T, Schroter

571 D (2014) A review of multiple natural hazards and risks in Germany. Nat Hazards 74:2279-

$572 \quad 2304$

573 Levin J (2009) Hammurabi. Inforbase Publishing, NewYork, pp54-55

574 Marzocchi W, Mastellone ML, Di Ruocco A, Novelli P, Romeo E, Gasparini P (2009)

575 Principles of multi-risk assessment, Interaction amongst natural and man-induced risks.

576 Natural Risk Assessment (NaRAs) project (2009)

577 http://ec.europa.eu/research/environment/pdf/multi-risk_assessment.pdf

578 Meunier P, Hovius N, Haines JA (2008) Topographic site effects and the location of 579 earthquake induced landslides. Earth and Planetary Science Letters. 275:3-4:221-232

580 Mignan A, Wiemer S, Giardini D (2014) The quantification of low-probability-high-

581 consequences events: part I. A generic multi-risk approach. Nat Hazards. 73:1999-2022

582 Miles SB (2011) Participatory model assessment of earthquake-induced landslide hazard

583 models. Nat Hazards. 56:749-766

584 Miyabuchi Y, Hanada D, Niimi H, Kobayashi T (2013) Stratigraphy, grain-size and 585 component characteristics of the 2011 Shinmoedake eruption deposits, Kirishima Volcano, 586 Japan. Journal of Volcanology and Geothermal Research. 258:31-46

587 Montrasio L, Valentino R (2008) A model for triggering mechanisms of shallow landslides.

588 Nat. Hazards Earth Syst. Sci. 8:1149-1159

589 Nagai K, Hattori Y, Ashikari M (2010) Stunt or elongate? Two opposite strategies by which 590 rice adapts to floods. J Plant Res 123:303-309

591 Nirupama N (2013) Tsunami versus storm surge: a brief review. Nat Hazards. 69:1123-1130

592 Ohbo N; Horikoshi N; Yamada T; Tachibana K; Akiba H (2004) Dynamic Behavior of a 593 Underground Motorway Junction due to Large Earthquake. 13th World Conference on 594 Earthquake Engineering Vancouver, B.C., Canada August 1-6, 2004 Paper No. 1215 
595 Organisation for Economic Cooperation and Development (2012) Global Modelling of 596 Natural Hazard Risks, Enhancing existing capabilities to address new challenges. OECD

597 Global Science Forum September 2012. http://www.oecd.org/sti/sci-

598 tech/Final\%20GRMI\%20report.pdf. Accessed 25 March 2015

599 Pearce AJ, Watson AJ (1986) Effects of earthquake-induced landslides on sediment budget

600 and transport over a 50-yr period. GEOLOGY. 14:2-55

601 Podolskiy EA, Nishimura K, Abe O, Chernous PA (2010) Earthquake-induced snow

602 avalanches: I. Historical case studies. Journal of Glaciology. 56:197:431-446

603 Reddya MC, Paula SA, Abrahama J, McNeesea M, DeFlitchb C, Yena J (2009) Challenges to 604 effective crisis management: Using information and communication technologies to 605 coordinate emergency medical services and emergency department teams, International 606 journal of medical informatics 78:259-269

607 Rodri'gueza CE, Bommerb JJ, Chandler RJ (1999) Earthquake-induced landslides: 19806081997 Soil Dynamics and Earthquake Engineering 18 (1999) 325-346

609 Seed RB, Cetin KO, Moss RES, Kammerer AM, Wu J, Pestana JM, Riemer MF, Sancio RB, 610 Bray JD, Kayen RE, Faris A (2003) Recent Advances in Soil Liquefaction Engineering: A 611 Unified and Consistent Framework, 26th Annual ASCE Los Angeles Geotechnical Spring 612 Seminar, Keynote Presentation, H.M.S. Queen Mary, Long Beach, California, April 30, 2003.

613 Shao WY (2010) Critical rainfall intensity for safe evacuation from underground spaces with 614 flood prevention measures. Journal of University-SCIENCE A (Applied Physics \& 615 Engineering) 11:9:668-676

616 The Shimbun Joho, No. 5618, 2014

617 Schmidt J, Matcham I, Reese S, King A, Bell R, Henderson R, Smart G, Cousins J, Smith W, 618 Heron D (2011) Quantitative multi-risk analysis for natural hazards: a framework for 619 multi-risk modelling. Natural Hazards. 58:1169-1192

620 Showalter PS, Myers MF (1992), Natural Disasters as the cause of technological emergencies: 621 a review of the decade 1980-1989. Natural Hazards Research and Applications Information 622 Center, Institute of Behavioral Science, University of Colorado, Working paper \#78

623 Stimberis J,1Rubin CM(2011) Glide avalanche response to an extreme rain-on-snow event, 624 Snoqualmie Pass, Washington, USA. Journal of Glaciology, 57(203):468-474

625 Sui J, Koehler G (2001) Rain-on-snow induced flood events in Southern Germany. Journal of 626 Hydrology. 252:205-220

627 Tohno I, Shamoto Y (1986) Liquefaction Damage to the Ground During the 1983 Nihonkai628 Chubu (Japan sea) Earthquake in Aomori Prefecture, Tohoku, Japan. Natural Disaster

629 Science. 8(1):85-116 
630 Udo K, Sugawara D, Tanaka H, Imai K (2012) Impact of the 2011 Tohoku Earthquake and 631 Tsunami on Beach Morphology along the Northern Sendai Coast. Coastal Engineering 632 Journal. 54(1):15

633 Wait Jr. RB, Pierson TC, Macleod NS, Janda RJ (1983) Voight B, Holcomb RT, Eruption634 Triggered Avalanche, Flood, and Lahar at Mount St. Helens - Effects of Winter Snowpack. 635 Science, 221:4618:1394-1397

636 Wilson T, Stewart C, Cole J, Johnston D, Cronin S (2010) Vulnerability of farm water supply 637 systems to volcanic ash fall. Environ Earth Sci. 61:675-688

638 Wirtz A, Kron W, Low P, Steuer M (2014) The need for data: natural disasters and the 639 challenges of database management. Natural Hazards. 70:135-157

640 Xu L, Meng X, Xu X (2014) Natural hazard chain research in China: A review. Nat Hazards. 641 70:1631-1659

642 Yoshitake Y (1992) Notes on Liquefaction for Reclamation Dike Design. Jour. JSIDRE 643 60(9):813-818

644 Young SR, Sparks RSJ, Aspinall WP, Lynch LL, Miller AD, Robertson REA, Shepherd JB 645 (1998) Overview of the eruption of Soufriere Hills volcano, Montserrat, 18 July 1995 to 646 December 1997. Geophysical Research Letters. 25:18:3389-3392

647 Zhou H, Wang W, Hecht M (2013) Three-dimensional derailment analysis of a crashed city 648 tram, Vehicle System Dynamics. International Journal of Vehicle Mechanics and Mobility. 649 51:8:1200-1215 